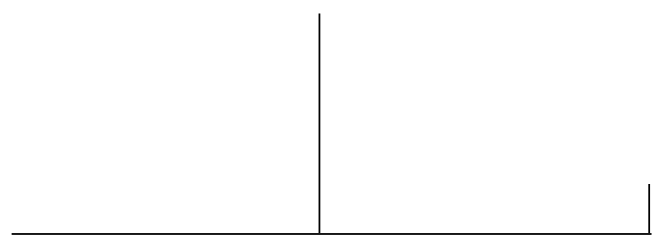

Rev. Latinoam. Psicopat. Fund., São Paulo, 16(1), 147-153, mar. 2013

\title{
O terapeuta afetado: hermenêutica como posição clínica
}

Ricardo da Silva Lucante Bulcão

O presente trabalho relata uma experiência clínica em um Hospital de Custódia e Tratamento Psiquiátrico. Após o suicídio de um de seus pacientes, o autor se depara com a questão da suposta neutralidade do analista para compreender que está passando por um processo de luto. A questão clínica a ser levantada será referente à postura do terapeuta como ser "afetável" - em oposição ao cientista neutro que não se pode deixar tocar. Tal aspecto será analisado a partir da posição hermenêtica de Hans-Georg Gadamer (1900-2002).

Palavras-chave: Neutralidade, hermenêutica, diálogo, luto 


\section{Se a história fosse vista como um repositório para algo mais do que anedotas ou cronologias, poderia produzir uma transformação decisiva na imagem de ciência que atualmente nos domina.}

(Thomas S. Kuhn)

Faz algum tempo, um de meus pacientes morreu. Suicídio. Enforcou-se com um lençol, pendurado na janela do banheiro. Morreu em um antigo Manicômio Judiciário, hoje Hospital de Custódia e Tratamento Psiquiátrico.

No Hospital de Custódia estão internados, em regime fechado, indivíduos considerados inimputáveis pela justiça, tanto homens como mulheres. Este termo significa que já não podem ser considerados responsáveis pelo ato criminoso que cometeram e que lhes levou à prisão. Portanto, após a confirmação por uma perícia psiquiátrica, são absolvidos perante a lei e condenados a uma medida de tratamento neste hospital, de onde só sairão após laudo médico favorável e autorização judicial.

Esta instituição, nos modos como é formada e conduzida, traz inúmeras questões bastante relevantes, como: Quais as consequências de se desresponsabilizar um individuo por seus atos? Existe um tratamento possível em uma instituição como esta, constituída como uma cadeia em todos os aspectos a não ser pelo perfil de seus internos e pela presença massiva de medicamentos? Quais as implicações clínicas de um tratamento quase forçado pela equipe médica presente, e do uso de medicamento como contingência punitiva? E ainda, como a incerteza sobre o tempo de internação pode afetar cada paciente?

Certamente, essas são apenas algumas das questões essenciais que poderiam ser levantadas a respeito de um hospital de custódia, de seus pacientes e de seus funcionários. No entanto, neste trabalho, pretendo me ater ao ocorrido, já mencionado, e à forma como afetou minhas posições teóricas e profissionais a res- 
peito do psicopatológico. Para tanto, não pretendo me ater ao caso em si, mas ao que ele suscitou - o que não deve eliminar a perspectiva clínica da reflexão.

Em um dia comum de trabalho, enquanto me preparava para uma de minhas atividades, recebi uma ligação da diretoria do hospital. Estava sozinho na sala. O aviso foi dado de forma curta, mas delicada - comunicado por alguém que (re)conhece as dificuldades do lido numa situação como essa. Não morreu na hora, mas pouco depois. Fiquei imediatamente abalado e cancelei minha próxima atividade. Parei sentado; sem pensar, sem saber o que sentia.

Algum tempo depois, quando pude refletir, pensei que não estava preparado para uma situação como essa. Afinal, não fazia ainda um ano que havia saído dos muros, mais do que seguros, da universidade - seguros no que diz respeito à vida profissional, é claro. Quando fui aceito para trabalhar neste hospital, sabia que passaria por uma experiência única, mas não tinha ideia de sua dimensão.

Fui inescapavelmente afetado. Algumas pessoas me perguntaram se me sentia assim por achar que "podia ter feito algo". Nada disso. Não tenho a pretensão de ter algum poder sobre as decisões de meus pacientes - e nem poderia ter. Seria apenas mais uma ilusão desfeita pela realidade de nossa impotência. Ação e desejo foram dele, assim como todo seu sofrimento por ter de viver naquele lugar, completamente abandonado pela família.

Perdê-lo foi o que me tocou. Sei agora que meu sentimento é de luto. A dor de não ter mais por perto alguém por quem temos carinho. $O$ interessante é que somente agora consigo lhe dar este nome e posso finalmente compreender que se trata disso: Não o luto vivenciado pela perda de um amigo ou parente próximo, mas, sim, de um paciente com quem me envolvi por quase um ano.

Neste pouco tempo de experiência profissional, pude perceber algumas particularidades do trabalho na instituição, neste caso quase prisional, e suas diferenças com o trabalho do consultório. Circulava diariamente por entre os pavilhões procurando pacientes, me dirigindo a algum pavilhão específico, assistindo ao jogo de futebol ou à roda de samba e participando das festas que ocorriam com certa frequência dentro dos muros do hospital. Era inevitável que cruzasse com os pacientes que atendia em psicoterapia nestes ambientes bem menos formais, descontraídos, cotidianos. Quando tal encontro se dava, conversávamos, riamos ou observávamos juntos alguma cena inusitada (coisa que nunca faltou). Percebi, então, que tinha dois "eus terapeutas": o do consultório e o do manicômio, este último muito mais próximo dos pacientes e distante da imagem formal do profissional da saúde - principalmente da do psicoterapeuta.

Algum tempo passado, refletindo sobre o acontecido, me parece fazer mais sentido a noção hermenêutica que Hans-Georg Gadamer (1900-2002) propõe. Com base em estudos da fenomenologia-existencial de Martin Heidegger (1889- 
1976) e grande apreço pela filosofia platônica e aristotélica, nos mostra que a neutralidade é uma ilusão impossível de ser alcançada.

Quando duas pessoas se encontram e trocam experiências, trata-se sempre do encontro entre dois mundos, duas visões e duas imagens de mundo. (Gadamer, 2007, p. 246)

Afirma, ainda, que a verdade só pode ser conhecida pelo diálogo, de dois horizontes que se fundem. Segundo Gadamer, essa "fusão de horizontes" se dá em todas as relações humanas - mesmo que entre alguém e uma obra de arte ou uma vara de pescar. Todos trazemos conosco nossos preconceitos, fruto de nossa inscrição cultural e histórica.

A pretensão de uma ausência total de preconceitos é uma ingenuidade, seja na forma delirante de um iluminismo absoluto, seja como delírio de um empirismo livre de todos os preconceitos da tradição metafísica, ou ainda como delírio de uma superação da ciência pela crítica ideológica. (Gadamer, 2007, p. 215)

Somente ao me dar conta deste aspecto ontológico, pude perceber que se tratava de luto o que sentia. E se por alguns instantes não o soube, foi pela dificuldade de deixar de lado minha noção positivista de terapeuta neutro, de função técnica, exterior ao objeto de estudo - no caso, de tratamento.

As implicações clínicas desta visão sobre o ser humano ainda parecem um pouco nebulosas, mas intuo que sejam predominantemente éticas. Reconhecer que somos afetados pela história de nossos pacientes, assim como por seus atos, pode ser a forma primordial para a emergência do legítimo diálogo, que, segundo Gadamer, trará à tona a verdade sobre seu sofrimento, sempre ressignificada pelos novos passos de sua história, ampliando, assim, sua gama de possibilidades de existência e reduzindo sua dor.

Desta forma, a compreensão clínica se faria radicalmente hermenêutica, já que não se basearia em técnicas pré-definidas sobre qualquer tema, mas, sim, no diálogo travado com a clínica da fala.

Mas se todo o entendimento é interpretação, então ele é ainda orientado por aquilo que Gadamer chama de uma "fusão de horizontes". Um texto, ou qualquer coisa, ou até mesmo um evento dentro do mundo que interpretamos, tem seu próprio horizonte de significado. A interpretação está situada dentro do horizonte mútuo do intérprete e da coisa a ser interpretada. (Lawn, 2007, p. 13)

É, portanto, dentro desta "fusão de horizontes" que devemos compreender nossa hermenêutica. E é dentro desta perspectiva que concebo sua importância para qualquer âmbito psicopatológico. Ou seja, esta postura, comprometida com a presente noção de diálogo - entendido como algo que está sempre inserido em uma tradição -, proporciona um olhar rigorosamente ético para com a com- 
preensão da situação clínica, referente ao pathos - sempre excessivo, desmedido e produtor do sujeito em seu sofrimento, sua paixão e sua passividade (Berlinck, 2008).

Desta forma, a direção compreensiva do caso clínico deixa de ser definida por uma relação teórico-clínica e passa a se desenhar como clínico-teórica. $\mathrm{Ou}$ seja, é a partir de uma experiência dialógica que podemos construir uma negociação teórica. Negociação no seu sentido radicalmente hermenêutico: mutante na historicidade de uma determinada comunidade.

Recusar a psicopatologia sob esta noção seria o mesmo que impedir o diálogo e, assim, o desvelamento do pathos. Portanto, a partir de então, pretendo cada vez mais me tornar o eu do manicômio ao ouvir o sofrimento de alguém que me procura; e, aos poucos, deixar de lado a pose e a postura do terapeuta inafetável.

\section{Referências}

Berlinck, M. T. (2008). Psicopatologia Fundamental (2. reimpressão). São Paulo: Escuta.

Gadamer, H-G. (2007). Verdade e Método II. Petrópolis, RJ: Vozes/Bragança Paulista, SP: Editora Universitária São Francisco.

Lawn, Chris (2007). Compreender Gadamer. Petrópolis, RJ: Vozes.

\section{Resumos}

(The therapist is affected: hermeneutics as a clinical position)

The present paper describes a clinical experience at a hospital for custody and psychiatric treatment. After the suicide of one of his patients, the author faces the question about the supposed neutrality of the analyst in order to understand that he himself is in a process of mourning. The clinical question to be raised refers to the therapist's posture as being "affectable," in opposition to some neutral and emotionally unmovable scientist. This aspect will be analyzed from Hans-Georg Gadamer's position of hermeneutics (1900-2002).

Key words: Neutrality, hermeneutics, dialogue, mourning

(Le thérapeute affecté: l'herméneutique en tant que position clinique)

Cet article porte sur une expérience clinique qui a eu lieu dans une institution psychiatrique pour malades mentaux criminels. Après le suicide de l'un de ses patients, 
l'auteur se voit confronté à la question de la soi-disant neutralité de l'analyste pour comprendre qu'il passe par un processus de deuil. La question clinique posée porte sur l'attitude du thérapeute en tant qu'être "affectable" - par opposition au scientiste neutre qui ne peut pas se permettre d'être affecter. Cet aspect est analysé à partir de la position herméneutique de Hans-Georg Gadamer (1900-2002).

Mots clés: Neutralité, herméneutique, dialogue, deuil

(El terapeuta afectado: la hermenéutica como una posición clínica)

Este artículo relata una experiencia clínica en un Hospital Psiquiátrico de Atención Forense. Tras el suicidio de uno de sus pacientes, el autor se enfrenta a la supuesta neutralidad del analista para entender que está atravesando por un proceso de luto. La cuestión clínica que se plantea está relacionada con la postura del terapeuta de poder ser "afectado", en oposición a la del científico neutro que no se debe dejar afectar por ese tipo de eventos. Este aspecto será analizado desde la perspectiva hermenéutica de Hans-Georg Gadamer (1900-2002).

Palabras clave: Neutralidad, hermenéutica, diálogo, luto

(Der affektierte Therapeut: Hermeneutik als klinische Haltung)

Vorliegende Arbeit berichtet von einer klinischen Erfahrung in einem Gefängniskrankenhaus für psychiatrische Behandlung. Nach dem Selbstmord einer seiner Patienten, trifft der Autor auf die Frage der angenommenen Neutralität des Analysten, um zu verstehen, dass er einen Trauerprozess durchmacht. Die klinische Frage, die hier zu stellen ist, bezieht sich auf die Haltung des Therapeuten als „affektierbares“ Wesen - im Gegensatz zum neutralen Forscher, der sich nicht affektieren lassen darf. Dieser Aspekt wird ausgehend von der hermeneutischen Stellung von Hans-Georg Gadamer(1900-2002) analysiert.

Schlüsselwörter: Neutralität, Hermeneutik, Dialog, Trauer

Citação/Citation: Bulcão, R. da S. L. O terapeuta afetado: hermenêutica como posição clínica. Revista Latinoamericana de Psicopatologia Fundamental, São Paulo, 16(1), 147-153, mar.2013.

Editor do artigo/Editor: Profa. Dra. Ana Cecilia Magtaz (Universidade de São Paulo), São Paulo, SP, Br. 
Recebido/Received: 14.12.2012 / 12.14.2012 Aceito/Accepted: 13.1.2013 / 1.13.2013

Copyright: () 2009 Associação Universitária de Pesquisa em Psicopatologia Fundamental/ University Association for Research in Fundamental Psychopathology. Este é um artigo de livre acesso, que permite uso irrestrito, distribuição e reprodução em qualquer meio, desde que o autor e a fonte sejam citados / This is an open-access article, which permits unrestricted use, distribution, and reproduction in any medium, provided the original author and source are credited.

Financiamento/Funding: O autor declara não ter sido financiado ou apoiado / The author has no support or funding to report.

Conflito de interesses/Conflict of interest: $\mathrm{O}$ autor declara que não há conflito de interesses / The author declares that has no conflict of interest.

\section{Ricardo da Silva Lucante Bulcão}

Psicólogo pela Pontifícia Universidade Católica de São Paulo - PUC-SP (São Paulo, SP, $\mathrm{Br}$ ); Especialização em Teoria Psicanalítica - Coordenadoria Geral de Especialização, Aperfeiçoamento e Extensão da mesma universidade; Psicólogo na Secretaria da Administração Penitenciária do Estado de São Paulo (São Paulo, SP, Br).

Travessa Ayres da Mata Machado Filho, 45 - Santana 02013-008 São Paulo, SP, Br.

Fone: (11) 99903-1281

e-mail: ricardobulcao@yahoo.com.br 